\title{
An Investigation into the Quality of History Taken During Antenatal Care in Selected Clinics of Lundazi District - Zambia
}

\author{
Patricia Mambwe ${ }^{1}$, Jordan Tembo ${ }^{2}$ \\ ${ }^{1}$ Department of Nursing, School of Health Sciences, Rusangu University, P.O. Box 660391, Monze, Zambia \\ ${ }^{2}$ Kalindawalo General Hospital, P.O. Box 560008, Petauke, Zambia \\ DOI: https://dx.doi.org/10.47772/IJRISS.2021.5417
}

\begin{abstract}
Quality Antenatal care (ANC) is premised on early identification of risk factors and timely treatment to prevent maternal and neonatal mortalities. This facility based crosssectional study evaluated the quality of history taken during Antenatal Care provision in selected clinics of Lundazi district, Zambia. Data was collected through Focus Group Discussion with ANC users and through observation during ANC visits. This study found that ANC history taken, lacked risk identification as illustrated by $68.3 \%$ of clients who reported not to have been probed on previous hypertensive disorders, still births, Antepartum haemorrhage and postpartum haemorrhage. Out of 12 clients with raised Diastolic Blood pressure of 110 and above, only $4(33.3 \%)$ of the clients were asked whether they had a headache and $5(42 \%)$ if they had experienced convulsions. None $(0 \%)$ of those clients were asked whether they experienced epigastric pain, blurred vision or dizziness- to rule out preeclampsia. $70 \%$ of the clients were not asked how they felt from the previous visit to current visit and whether they felt fetal movements. Inadequate history taken at initial and subsequent ANC visits reduces opportunities for early identification and treatment of risk factors leading to maternal and fetal complications. Strengthening the quality of history taken during Antenatal contacts, improves provision of quality care to pregnant women.
\end{abstract}

Key words: Antenatal care, Antenatal care Users, History taking, Quality care.

\section{INTRODUCTION}

A ntenatal care is the care given to a pregnant mother throughout pregnancy for optimal maternal and foetal health. During Antenatal contacts with health workers at a health facility, nurses assess the health of the expectant mother and her family by compiling a comprehensive data base, which include the health history, physical examination and laboratory studies (Ricci, 2013; Frazer and Cooper, 2009; Sherwen et al., 1995). Scholars observe that the information from the health history helps the physician or nurse to individualize prenatal physical examination, identify risk factors early and develop an appropriate plan of care. From an antenatal mother, history is collected at initial visit and subsequent visits during follow up care. It covers the following parameters- demographic, medical, surgical, social, past and present obstetric history, family planning history, family history (Frazer and Cooper, 2009). The essence of collecting extensive information from a pregnant woman is to assist the health worker detect any risks early and manage the woman accordingly (Frazer and Cooper, 2009). Full history should be taken from a pregnant woman during subsequent pregnancies as well because certain conditions in pregnancy tend to repeat in later pregnancies and complicate the current pregnancy (Ricci, 2013).

Quality history taken during antenatal visits provide opportunity for monitoring progress of pregnancy so that any deviation from the normal can be detected at an early stage before serious complications occur (Ricci, 2013). Nonexhaustive history taken from an antenatal mother is a slide into the road characterized by poor antenatal care, maternal and foetal complications with subsequent increased maternal and neonatal deaths. Lundazi district- Zambia, is one example where the number of maternal deaths throve over the years. The district recorded a total of 170 maternal deaths between 2010 and 2018. The district scored a shocking number of maternal deaths despite a favourable Antenatal coverage percentage of $86 \%$. Logically, the wide ANC coverage was a reassurance for the district to score a corresponding low number of maternal deaths taking into account that all components of safe motherhood such as Antenatal care, labour management and Post-natal Care were accurately and correctly done. But that was not the case. The staggering trail of maternal deaths over the years in Lundazi district, despite increased ANC utilization clearly indicated possibility of compromised Antenatal Care. This curious drive prompted the researchers to carry out an investigation into the quality of history taken during antenatal care in Lundazi district.

\section{MATERIALS AND METHODS}

Methods: A facility based cross- sectional study was conducted between October 2019 and June 2020 in Lundazi District, Zambia. The study investigated the Quality of history taken during Antenatal Care in selected clinics of Lundazi district. Data was collected through Focus Group Discussion and through observations during ANC consultations. Simple random sampling method was used to draw out a sample of 60 ANC users stratified as follows: 30 attending Antenatal care on an initial visit and 30 for subsequent antenatal care visits. Study settings were purposively selected - health facilities 
with high numbers of maternal referrals. The health facilities included (Munyukwa Rural Health Center (RHC) with 2 referrals both at 36 weeks gestation, a gravida 3 para 2 and a gravida 1 para 0 , ZASP Health Post with 3 referrals all at 40 weeks gestation, a gravida 6 para 5 , a gravida 5 para 3 and a gravida 1 para 0, Egichikeni RHC, Chasera RHC, Nyangwe RHC with 2 referrals each both at 36 weeks gestation, a gravida 3 Para 2 and a gravida 1 Para 0 . Some of the referred antenatal mothers from these facilities later died at the receiving referral health facility.

The Maternal and New born Quality of Care Survey Antenatal Care Observation Checklist was used for data collection and a Focus Group Discussion guide was used for data collection. The Focus Group Discussion comprised of 12 participants in each group. Each meeting lasted 60 minutes. Refreshments were offered to all participants. The researcher conducted five (5) Focus Group Discussions- one Focus Group Discussion at each selected health facility. The Focus Group Discussions were conducted by the researchers assisted by two recruited Research Assistants- holders of Bachelor of Science in nursing degree holders and an advanced Diploma in Midwifery. Upon arrival at the venue selected for Focus Group Discussion, participants were first informed about the nature of the study including the associated risks and benefits. Informed consent was a two-stage process: participants needed first to consent to participate in the focus group discussion verbally. The second stage required participants to give separate verbal consent to have the focus group digitally recorded for later transcription and coding. Quantitative data was entered and analyzed using basic descriptive statistics. For qualitative data, identified themes and sub-themes were reviewed and grouped together. Qualitative data was then triangulated with quantitative data to give an in-depth understanding of the quality of antenatal care provided to pregnant women.

\section{RESULTS}

This study found that ANC history taken lacked risk identification as illustrated by $68.3 \%$ of clients who reported not to have been probed on previous hypertensive disorders, still births, Ante and postpartum hemorrhage. Out of 12 ANC users with raised blood pressure readings with diastolic blood pressure of $110 \mathrm{mmHg}$, only $4(33.3 \%)$ of clients were asked whether they had a headache and 5(42\%) were asked if they had experienced convulsions. None among 12 clients with raised blood pressure were asked whether they had experienced epigastric pain, blurred vision or dizziness- to rule out eclampsia. Furthermore, $70 \%$ of the clients were not asked on how they felt from previous visit to current visit. There were not asked whether they felt fetal movements. Critical symptoms such as difficulties in breathing, severe abdominal pain and decreased in fetal movement were the least to be asked for among the danger signs in pregnancy (table 1).
Table 1: Parameters explored during history taking $(\mathrm{n}=60)$

\begin{tabular}{|c|c|c|c|}
\hline $\begin{array}{c}\text { History } \\
\text { collected } \\
1^{\text {st }} \& \\
\text { subsequent } \\
\text { visits }\end{array}$ & Checklist items & Yes & No \\
\hline \multirow{3}{*}{$\begin{array}{l}\text { Medical } \\
\text { history }\end{array}$} & $\begin{array}{l}\text { Any medication the } \\
\text { client is currently taking. }\end{array}$ & $28(46.7 \%)$ & $32(53.3 \%)$ \\
\hline & HIV status & $60(100 \%)$ & - \\
\hline & $\begin{array}{c}\text { History of } \\
\text { Diabetes/epilepsy/TB }\end{array}$ & $32(53.3 \%)$ & $28(46.7 \%)$ \\
\hline \multirow{5}{*}{$\begin{array}{l}\text { Obstetric } \\
\text { history }\end{array}$} & $\begin{array}{c}\text { Gravidity/parity/baby/Se } \\
\text { x of babies/Mode of } \\
\text { deliveries }\end{array}$ & $\begin{array}{l}60(100 \%) \\
60(100 \%)\end{array}$ & - \\
\hline & $\begin{array}{c}\text { Previous hypertensive } \\
\text { disorders }\end{array}$ & $19(31.7 \%)$ & $41(68.3 \%)$ \\
\hline & Previous PPH or APH & $14(23.3 \%)$ & $46(76.7 \%)$ \\
\hline & Still birth /Abortion & $22(36.7 \%)$ & $38(63.3 \%)$ \\
\hline & $\begin{array}{l}\text { Previous birth- } \\
\text { Gestational age }\end{array}$ & $32(53.8 \%)$ & $28(46.7 \%)$ \\
\hline \multirow{10}{*}{$\begin{array}{l}\text { Mention } \\
\text { any of the } \\
\text { following } \\
\text { for current } \\
\text { pregnancy } \\
\text { (Danger } \\
\text { signs) }\end{array}$} & Vaginal bleeding & $49(81.7 \%)$ & $11(18.3 \%)$ \\
\hline & Fever & None & $60(100 \%)$ \\
\hline & Headaches & $20(33.3 \%)$ & $40(66.7 \%)$ \\
\hline & Blurred vision & None & $60(100 \%)$ \\
\hline & $\begin{array}{l}\text { Swollen face or } \\
\text { hands(oedema) }\end{array}$ & $42(70 \%)$ & $18(30 \%)$ \\
\hline & Convulsions & $23(38.3)$ & $37(61.7 \%)$ \\
\hline & Difficulty breathing & None & $60(100 \%)$ \\
\hline & Severe abdominal pain & None & $60(100 \%)$ \\
\hline & $\begin{array}{c}\text { Decrease in fetal } \\
\text { movements }\end{array}$ & None & $60(100 \%)$ \\
\hline & $\begin{array}{l}\text { Any other problem the } \\
\text { client is concerned with }\end{array}$ & None & $60(100 \%)$ \\
\hline
\end{tabular}

Over two-thirds of clients- $68.3 \%$, were not asked about previous hypertensive disorders. Similarly, $76.7 \%$ of ANC users were not asked about history of previous Post-Partum Haemorrhage and Ante Partum Haemorrhage. Nearly twothirds $(63.3 \%)$ of the clients were not asked whether they had an abortion or a Still Birth during previous pregnancies. Over half of clients (53.3\%), were not asked if they were on any medication during current pregnancy.

Commenting on the type of questions ANC users were asked; they shared their story as follows:

The nurse asked me how many children I have, sex of the children and whether I underwent an operation in the past. She also asked me about the last day of menstruation, and my HIV status. That is all. These others she didn't (Participant 6, 29years old, Facility B)

One ANC user coming for subsequent ANC visit reported:

When you are starting antenatal care, they (nurses) ask about history of abortions and whether you have STDs (Sexually Transmitted Diseases. As for today, no one asked me whether 
the baby is moving or playing (Participant 7, 31years old, Facility A ).

With regard to questions from providers to find out how Antenatal clients were feeling that day, figure 1 depicts the findings.

Figure 1: ANC users being asked how they are feeling $(\mathrm{n}=60)$

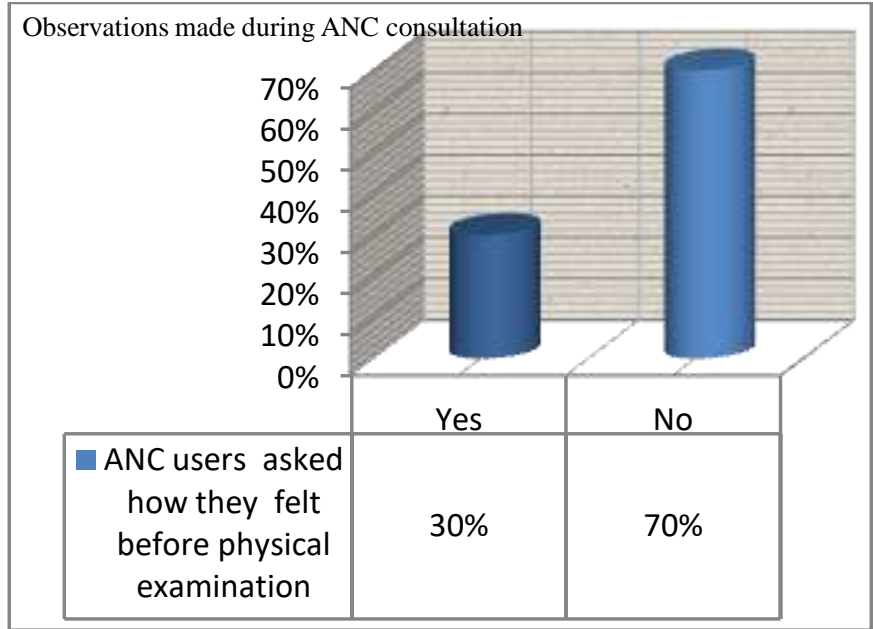

Observations made by the researcher during ANC consultations reviewed that $42(70 \%)$ of the clients were not asked how they were feeling (See figure 1).

Providing their own experiences one participant from Facility 'D' commented;

The nurses will palpate your abdomen but rarely will they ask how you are feeling (Participant 8, 39years old, Facility D).

The study further observed follow up questions for clients with high Blood pressure and diastolic blood pressure above $110 \mathrm{mmhg}$. Findings are depicted figure 2 below;

Figure 2: follow up questions for clients with diastolic blood pressure ranging above $110 \mathrm{mmhg}(\mathrm{n}=12)$

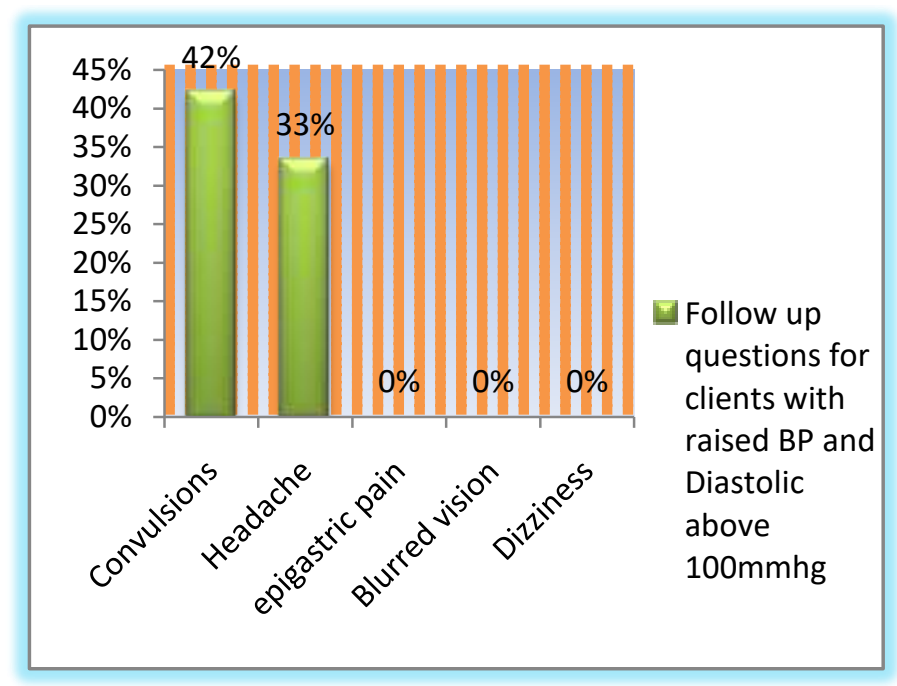

\section{DISCUSSION}

Effective pre-, intra-, and post-natal care interventions play an important role in reducing child mortality and morbidity (Arunda et al., 2017). Antenatal care also called pre-natal care serves as a key entry point for a pregnant woman to receive a broad range of services should be initiated at the onset of pregnancy (Warri and George, 2020). During pre-natal care, comprehensive history taken at both initial and subsequent ANC service provision increases the chance of risk identification which eventually leads to early diagnosis and treatment. Although ANC utilization was at $86 \%$ in Lundazi district, this study found inadequate history taken from antenatal mothers compromising quality of antenatal care. History collected from ANC users in Lundazi district- Zambia lacked risk identification as indicated by $68.3 \%$ of clients who were not asked about previous hypertensive disorders, still birth, Ante and Postpartum haemorrhage. What was most intriguing was that out of 12 clients who recorded raised Blood Pressure with a diastolic blood pressure of more than $110 \mathrm{mmhg}$, only $4(33.3 \%)$ were asked whether they had a headache while $5(42 \%)$ were asked for history of convulsions. Malha and August (2015) observed that lack of understanding on how to diagnose and treat hypertensive disorders in pregnancy may lead to a higher maternal and fetal morbidity and mortality.

This study found that antenatal mothers coming for care on subsequent visits were not asked whether they felt foetal movements as expressed by one antenatal mother, when the nurse records weight, she checks the BP and then asks the mother to join the queue going for palpations. We are not asked whether we feel the baby kicking inside (Participant 2, 31 years, Facility C). Similar findings have been reported from studies conducted in East Africa. A study by Bbaale (2011) in Uganda found that few pregnant women were asked about presence of fetal movements. Mothibe and Maputle (2006) observed that foetal movement is a valuable tool for early detection of foetal compromise. This study also found that $70 \%$ of the clients were not asked how they were feeling that day. The occurrence of the common danger symptoms can be felt by a mother. According to the Antenatal care module 15, health workers can assist a mother detect any symptoms by asking her to describe or explain how they were feeling that day they were visiting the facility. A study by Miltenburg et al., (2016) in Tanzania also found that history taken from pregnant women rarely included risk identification. Questions bordering on difficulties in breathing, severe abdominal pain and decreased fetal movements were the least asked.

Similar findings by Arunda et al., (2017) in their study entitled Effectiveness of antenatal care services in reducing neonatal mortality in Kenya reports that about 38 percent of all neonatal deaths in Kenya were attributable to lack of check-ups for pregnancy complications through incomplete history taken to aid in identifying risk factors during pregnancy thereby affecting overall antenatal care. Graham 
and Varghese (2012) observed that quality of ANC care has not received greater attention as a key reason for maternal mortality and morbidity remaining high in several countries despite substantial increases in coverage of maternal health services. ANC care defeats the objective of ANC, whose premise is early detection and treatment of complications (WHO, 2015; Kyei et al., 2012).

\section{CONCLUSION}

Antenatal care is composite care consisting of history taking, physical examinations, laboratory testing, health education, Counselling and drug supplementation among others. These care activities are mechanically close to each other and should be conducted according to set standards to score overall quality antenatal care. Incomplete history taken from antenatal mothers at either initial visit or subsequent visits or both affect the quality of physical examination, individualized health education, treatment, and largely minimizes risk reduction with subsequent maternal and foetal complications and death. Comprehensive history taken from antenatal mothers at any visit adds to the firewall of providing quality ANC services to pregnant women.

\section{RECOMMENDATIONS}

The study recommends that Ministry of health - District health office to conduct refresher courses to new as well as old staff on ANC provision. The component of risk identification and timely treatment during Antenatal Care should be emphasized by the Nursing and Midwifery Council. Similarly, Nursing and Midwifery training institutions should strengthen student exposure and assessment on ANC provision.

\section{AUTHOR'S CONTRIBUTION}

PM was responsible for the study conception and design, analysis and drafting of the manuscript. Both JT and PM participated in data collection. JT gave guidance on the analysis of qualitative data. Both authors read and approved the final Manuscript.

\section{ACKNOWLEDGEMENTS}

The author is grateful to the Eastern Provincial Health Office and Lundazi District health office team for approving the request to undertake this study. Many thanks go to the participants for their willingness and time to participate in this study.

This information was extracted from a study by Patricia Mambwe entitled; Quality of antenatal care provided to pregnant women in Lundazi district health facilities, Eastern province: Provider and user perspectives.

\section{REFERENCES}

[1] Antenatal care module 15: Counselling pregnant women on danger symptoms accessed from https://www.open.edu/openlearncreate/mod/oucontent/view.php?id $=46 \&$ printable $=1$ retrieved on 15/11/2020 @ 11:44 AM
[2] Arunda Malachi, Emmelin Anders, Asamoah Benedict Oppong. Effectiveness of Antenatal Care services in reducing neonatal mortality in Kenya: analysis of national survey data. Global Health Action. 2017;10(1):1328796. doi: $10.1080 / 16549716.2017 .1328796$ accessed from https://www.ncbi.nlm.nih.gov/pmc/articles/PMC5496054/ on 30/10/2020 at 04 AM hours.

[3] Babalola.S. and Fatusi.A, (2009) "Determinants of use of maternal health services in Nigeria-looking beyond individual and household factors," BMC Pregnancy and Childbirth, vol. 9, no. 1, article no. 43, 2009. Accessed from https://bmcpregnancychildbirth.biomedcentral.com/articles/10.118 6/1471-2393-9-43 on 12/12/2019 @ 21:30 hours

[4] Braunthal. S and Brateanu.A (2019) Hypertension in pregnancy: Pathophysiology and treatment.doi: 10.1177/2050312119843700 Accessed

from https://www.ncbi.nlm.nih.gov/pmc/articles/PMC6458675/ on 15/11/2020@04:20 AM

[5] Fraser, D.M. and Cooper, M.A.(eds.)., 2009, Myles Text Book for Midwives $\left(14^{\text {th }}\right.$ ed.) ISBN 0443072353. London: Churchill Livingstone

[6] Graham WJ and Varghese B. Quality, quality, quality: gaps in the continuum of care. Lancet. 2012;379(9811):e5-6. doi: 10.1016/S0140-6736(10)62267-2. Accessed from https://pubmed.ncbi.nlm.nih.gov/21474173/ on 30/10/2020 at 04:40 AM hours

[7] Kyei N, Chansa C, Gabrysch S. Quality of antenatal care in Zambia: a national assessment. BMC Pregnancy Childbirth (2012) 12:151. 10.1186/1471-2393-12-151 [PMC free article] [PubMed] [CrossRef] [Google Scholar] accessed on 10/10 2019@ 22:00 hours.

[8] Malha.L and August. P (2015), Secondary Hypertension in pregnancy 2015 Jul;17(7):53. doi:10.1007/s11906-015-0563-Z. accessed from https://pubmed.ncbi.nlm.nih.gov/26068655/ on 15/11/2020@04:20 AM.

[9] Milltenburg.A.S, Van der Eem. L, Nyanza.E.C, Pelt.S, Ndaki.P e tal., (2017), Antenatal care and opportunities for quality improvement of service provision in resource limited settings: A mixed methods study accessed on 16/11/19 at 06:57 hours from https://journals.plos.org/plosone/article/file?type=printable\&id=10. 1371/journal.pone.0188279.

[10] Mothiba. T and Maputle. M.S (2006), Mothers' knowledge of foetal movements monitoring during pregnancy in relation to perinatal outcome accessed from

https://www.researchgate.net/publication/47787590_Mothers\%27_ knowledge_of_foetal_movements_monitoring_during_pregnancy_ in_relation_to_perinatal_outcome.DOI: $10.4102 / \mathrm{hsag} . v 11 \mathrm{i} 2.219$ retrieved on 15/11/2020 at 05:32 hours.

[11] Phommachanh et tal., (2019), Improvement of Quality of Antenatal Care (ANC) Service Provision at the Public Health Facilities in Lao PDR: Perspective and Experiences of Supply and Demand Sides Accessed from https://www.ncbi.nlm.nih.gov/pmc/articles/PMC6647136/ on 30/10/2020 at 03:40 AM hours.

[12] Ricci, S.S., 2013, Maternity, Newborn, and Women's Health Nursing ( $3^{\text {rd }}$ ed.) ISBN 1-60831-801-X, Philadephia:Wolters Kluwer Health- Lippincott Williams \&Wilkins.

[13] Sherwen. I, Scoloveno.M and Weingarten. C ( 1995), Maternity Nursing: Care of the childbearing family, $\left(3^{\text {rd }}\right.$ ed) ISBN 0-83857083-6, United states of America.

[14] Warri and George (2020) Perceptions of pregnant women of reasons for late initiation of antenatal care: a qualitative interview study retrieved from https://bmcpregnancychildbirth.biomedcentral.com/articles/10.118 6/s12884-020-2746-0 on 15/11/2020 @ 11:13 AM

[15] WHO (2015) WHO Recommendations on Antenatal Care for a Positive Pregnancy Experience accessed from https://www.ncbi.nlm.nih.gov/books /NBK409110 / on 14/11/12 at15:46 hours. 